\title{
Cost-Effectiveness of Different Strategies for the Prevention of Venous Thromboembolism After Total Hip Replacement in China
}

\author{
Xiaoyu Yan $\cdot$ Xiaohua $\mathrm{Gu} \cdot$ Zhenxing $\mathrm{Xu} \cdot$ \\ Houweng Lin · Bin Wu
}

Received: September 18, 2016 / Published online: December 20, 2016

(C) The Author(s) 2016. This article is published with open access at Springerlink.com

\begin{abstract}
Introduction: The aim of this study was to evaluate the cost-effectiveness of rivaroxaban and apixaban versus enoxaparin for the universal prophylaxis of venous thromboembolism (VTE) and associated long-term complications in Chinese patients after total hip replacement (THR).
\end{abstract}

Enhanced content To view enhanced content for this article go to http://www.medengine.com/Redeem/ 8237F0604B39EFA6.

X. Yan

Department of Orthopedics, Shanghai Jiao Tong

University Affiliated Sixth People's Hospital,

Yishang Road 600, Shanghai, China

X. Gu

Department of Respiratory Medicine, Shanghai Jiao Tong University Affiliated Sixth People's Hospital,

Yishang Road 600, Shanghai, China

\section{Z. Xu}

Department of Cardiology, Renji Hospital, South Campus, School of Medicine, Shanghai Jiaotong

University, Shanghai, China

H. Lin · B. Wu (ه)

Medical Decision and Economic Group, Department of Pharmacy, Renji Hospital, School of Medicine, Shanghai Jiaotong University, Jiangyue Road 2000, Shanghai, China

e-mail: wbwithtg@hotmail.com
Methods: A decision model, which included both acute VTE (represented as a decision tree) and the long-term complications of VTE (represented as a Markov model), was developed to assess the economic outcomes of the three prophylactic strategies for Chinese patients after THR. Transition probabilities for acute VTE were derived from two randomized controlled studies, RECORD1 and ADVANCE3, of patients after THR. The transition probabilities of long-term complications after acute VTE, utilities, and costs were derived from the published literature and local healthcare settings. One-way and probabilistic sensitivity analyses (PSA) were performed to test the uncertainty concerning the model parameters. The quality-adjusted life years (QALYs) and direct medical costs were reported over a 5-year horizon, and incremental cost-effectiveness ratios (ICERs) were also calculated.

Results: Thromboprophylaxis with apixaban was estimated to have a higher cost (US \$178.70) and more health benefits (0.0025 QALY) than thromboprophylaxis with enoxaparin over a 5-year time horizon, which resulted in an ICER of US \$71,244 per QALY 
gained and was more than three times the GDP per capita of China in 2014 (US \$22,140). Owing to the higher cost and lower generated QALYs, rivaroxaban was inferior to enoxaparin among post-THR patients. The sensitivity analyses confirmed these results.

Conclusions: The analysis found that apixaban was not cost-effective and that rivaroxaban was inferior to enoxaparin. This finding indicates that compared with enoxaparin, the use of apixaban for VTE prophylaxis after THR does not represent a good value for the cost at the acceptable threshold in China; in addition, the cost of rivaroxaban was higher with lower QALYs.

Keywords: Anticoagulation; Cardiology; Cost-effectiveness analysis; Venous thromboembolism

\section{INTRODUCTION}

Major orthopedic surgery, such as total knee replacement (TKR) and total hip replacement (THR), is associated with a high risk of venous thromboembolism (VTE), which comprises deep vein thrombosis (DVT) and pulmonary embolism (PE) [1]. Long-term consequences arising from VTE include recurrent VTE, post-thrombotic syndrome (PTS), and chronic thromboembolic pulmonary hypertension (СTEPH), which further increase the disease burden related to VTE [2]. One prospective epidemiological study that included 837 Asian patients without thromboprophylaxis and who were undergoing elective THR, TKR, or hip fracture surgery (HFS) from 19 centers across Asia reported an incidence of total DVT of $41.0 \% \quad(95 \%$ confidence interval [CI] $35.4-46.7)$, including $63.8 \%$ of patients without symptoms [3]. Despite the availability of current thromboprophylactic interventions, the incidence rate of symptomatic DVT in Chinese patients after THR is $2.40-6.49 \%$, which is much higher than the $0.20-0.22 \%$ reported in Asia and the $0.26-1.30 \%$ reported in Western countries; furthermore, the rate of symptomatic PE in China is $0.30-0.47 \%$, which is higher than the $0.00-0.04 \%$ reported in Asia and similar to the $0.14-2.00 \%$ reported in Western countries [4]. Thus, it is critical to improve VTE prophylaxis for patients with THR in China.

Low molecular weight heparins (LMWH), such as enoxaparin, are frequently used for thromboprophylaxis in Chinese patients undergoing THR [5]. In recent years, rivaroxaban $\left(\right.$ Xarelto $^{\circledR}$, Bayer Schering Pharma AG) and apixaban (Eliquis $^{\circledR}$, Bristol-Myers Squibb/Pfizer EEIG), two oral factor Xa inhibitors, were licensed for VTE prophylaxis in China for patients undergoing THR. Pivotal studies have found that these new oral anticoagulants have a higher efficacy in reducing the risk of symptomatic VTE but a higher bleeding tendency in comparison with enoxaparin [6]. However, owing to the rapidly increasing healthcare demand and limited resources in China, the use of these new oral anticoagulants should be carefully considered in the decision-making process by balancing the clinical benefits and the related costs. Although there have been several published economic evaluations of the new oral thromboprophylactic agents for patients undergoing major orthopedic surgery in different settings [7-13], these evaluations have been mainly conducted in developed countries.

The objective of this study was to assess the cost-effectiveness of apixaban and rivaroxaban versus enoxaparin for prophylaxis against VTE in patients undergoing THR, from the perspective of the Chinese healthcare system. 


\section{METHODS}

\section{Economic Model Overview}

A decision-analytic model was developed to evaluate the cost-effectiveness of apixaban and rivaroxaban versus enoxaparin for the prevention of VTE in patients undergoing THR. The model included a 180-day decision-tree module for the acute phase (Fig. 1a) and a Markov process module for complications in the long-term phase (Fig. 1b), which was similar to the approach adopted in previously published studies [8-10]. Because only a paucity of information is available on the long-term clinical course of the disease and only recent events were considered pragmatically from a decision-maker's perspective, a 5-year time horizon was used in the long-term phase [14]. At the beginning of the decision tree, the patients would receive one of the three following agents for the

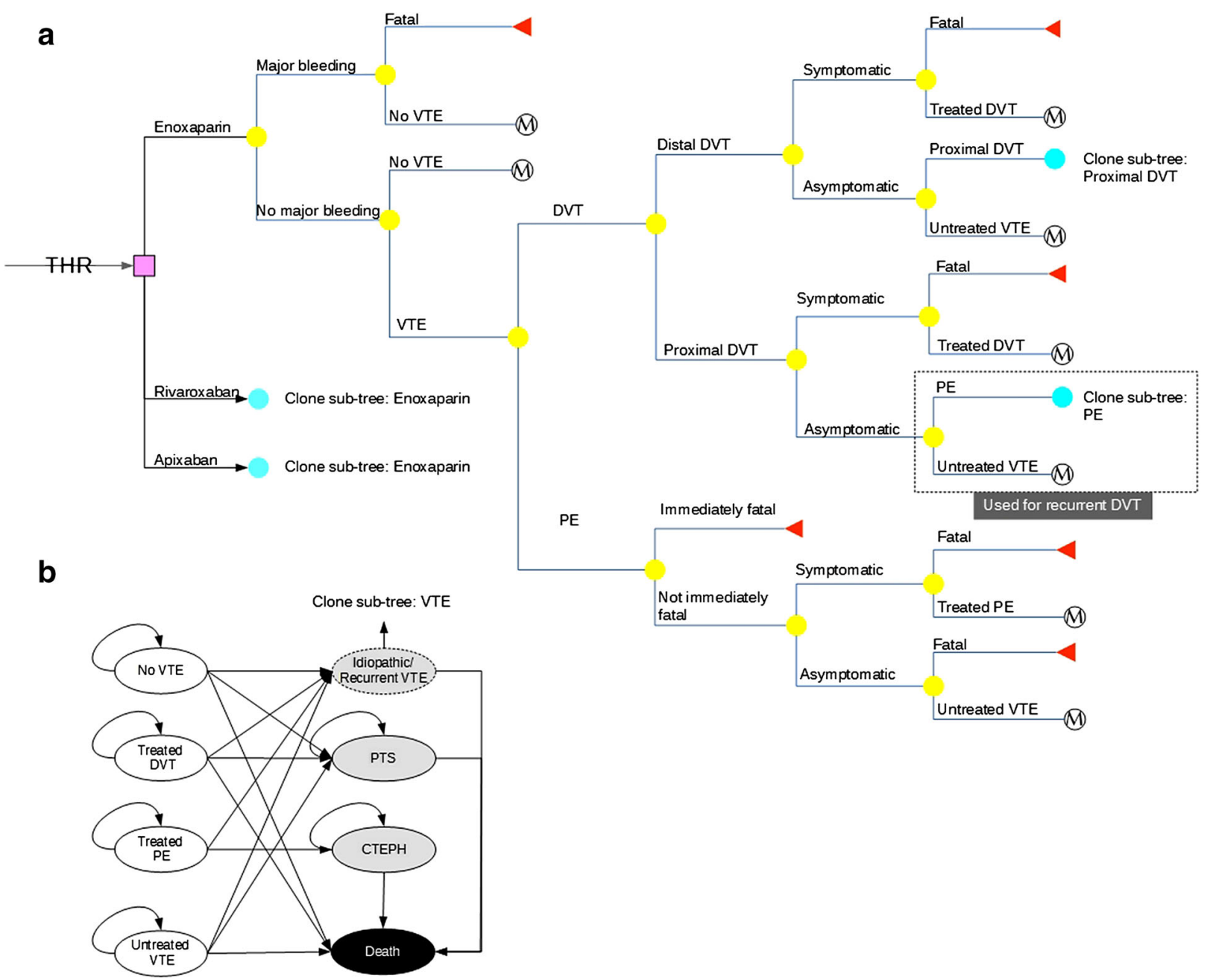

Fig. 1 Structure of the decision model with the decision tree for the acute phase (a) and the Markov model for long-term complications (b). DVT deep vein thrombosis, $P E$ pulmonary embolism, VTE venous thromboembolism,
CTEPH chronic thromboembolic pulmonary hypertension, PTS post-thrombotic syndrome, THR total hip replacement, $M$ Markov model, $D$ decision tree 
prophylaxis of VTE after THR: enoxaparin, rivaroxaban, or apixaban. Upon receiving prophylaxis, the risk of incurring a prophylaxis-related major bleeding event, which might lead to death or no sequelae, was considered.

Surgery-related VTE, including distal DVT, proximal DVT, and PE, may develop in patients treated with THR. It was assumed that only symptomatic VTEs would be treated, whereas asymptomatic VTEs would remain untreated and would not incur costs or decreased utility. Distal DVTs were assumed to have a risk of propagating to the proximal veins [8], whereas there was a risk of proximal DVTs propagating to PE [15]. The initial health states in the Markov model included "no VTE", "treated DVT", "treated PE", "untreated VTE", and "death (absorbing state)", which would be assigned for patients surviving the decision-tree process. Patients surviving from a $\mathrm{PE}$ and symptomatic DVT in the decision tree would be assigned to the "treated $\mathrm{PE}$ " and "treated DVT" states, respectively. Patients surviving from an asymptomatic, untreated VTE would be assigned the "untreated VTE" state. Patients who had no VTE event or incurred major bleeding without any sequelae in the decision tree would be assigned the "no VTE" state. Patients who incurred a fatal VTE or bleeding would be assigned the "death" state.

In each 1-year cycle of the Markov process, patients could incur a new or recurrent VTE. The incidence of recurrent VTE was modeled as a transitory event rather than a health state. Patients in the "treated DVT" or the "untreated VTE" states could incur a recurrent VTE or PTS. Patients in the "treated PE" could incur a recurrent VTE or CTEPH. Patients in the "no VTE" state could incur an idiopathic VTE or idiopathic PTS. The model assumed that a recurrent or an idiopathic VTE would have the same disease course profile and treatment pattern as the tree shown in Fig. 1a, and patients in the "PTS" or "CTEPH" state would remain in their state until death. The all-cause mortality risk was assumed to be the same for all patients regardless of their health state.

Quality-adjusted life-years (QALYs) and costs were discounted using an annual rate of $5 \%$ in accordance with Chinese guidelines for pharmacoeconomic evaluations [16]. Incremental cost-effectiveness ratios (ICERs) presented as cost per QALY gained were calculated to compare the two interventions, e.g., A vs. B for thromboprophylaxis. When the ICER was less than three times the per capita gross domestic product (GDP) of China, intervention $\mathrm{A}$ would be considered to be cost-effective compared with intervention B [17].

\section{Clinical Inputs}

In the decision tree model, the weighted average efficacy and safety inputs of enoxaparin for the acute phase model (Fig. 1a) were estimated from pooled data derived from two multinational clinical trials (the RECORD1 and ADVANCE3 study), which used the same enoxaparin regimen (40 mg QD) as the control strategy [18, 19]. On the basis of Chinese clinical practices and the local setting, $40 \mathrm{mg}$ of enoxaparin per day is recommended for thromboprophylaxis for patients receiving major orthopedic surgery [5]. Table 1 summarizes the clinical data used in the model. Because of the absence of head-to-head treatment efficacy (VTE events) and major bleeding data comparing rivaroxaban, apixaban, and enoxaparin, a network meta-analysis of randomized controlled trials was used to estimate the relative risks of a VTE event and major bleedings among patients 
Table 1 Clinical data used in the model

\begin{tabular}{|c|c|c|c|}
\hline Parameters & Base-case value & Range tested & References \\
\hline \multicolumn{4}{|l|}{ Acute phase } \\
\hline Enoxaparin & & & {$[18,19]$} \\
\hline Proximal DVT (\%) & 1.393 & $0.964-1.822$ & \\
\hline Distal DVT (\%) & 1.551 & $1.288-1.815$ & \\
\hline $\mathrm{PE}(\%)$ & 0.100 & $0.021-0.179$ & \\
\hline MB (\%) & 0.431 & $0.198-0.664$ & \\
\hline Hazard ratio of rivaroxaban versus enoxaparin & & & {$[18,19]^{\mathrm{a}}$} \\
\hline Proximal DVT & 0.022 & $0.0008-0.12$ & \\
\hline Distal DVT & 0.480 & $0.22-0.98$ & \\
\hline PE & 4.500 & $0.42-180$ & \\
\hline $\mathrm{MB}$ & 3.400 & $0.76-23$ & \\
\hline Hazard ratio of apixaban versus enoxaparin & & & {$[18,19]^{a}$} \\
\hline Proximal DVT & 0.340 & $0.13-0.75$ & \\
\hline Distal DVT & 0.270 & $0.12-0.54$ & \\
\hline PE & 0.590 & $0.083-4$ & \\
\hline MB & 1.200 & $0.65-2.3$ & \\
\hline DVT is symptomatic of enoxaparin in 180 days (\%) & 14.530 & $11.624-17.436$ & \\
\hline DVT is symptomatic of rivaroxaban in 180 days (\%) & 14.550 & $11.640-17.460$ & \\
\hline DVT is symptomatic of apixaban in 180 days (\%) & 13.050 & $10.440-15.660$ & \\
\hline \multicolumn{4}{|l|}{ Long-term phase } \\
\hline Proximal DVT is symptomatic & 0.400 & $0.243-0.557$ & [27-29] \\
\hline Distal DVT is symptomatic & 0.050 & $0.0304-0.0696$ & [27-29] \\
\hline $\mathrm{PE}$ is symptomatic & 0.320 & $0.195-0.445$ & {$[30]$} \\
\hline Distal DVT propagates to the proximal vein & 0.180 & $0.109-0.251$ & {$[31]$} \\
\hline Proximal DVT propagates to $\mathrm{PE}$ & 0.530 & $0.322-0.738$ & {$[15]$} \\
\hline Case-fatality of $\mathrm{MB}$ & 0.008 & $0.0049-0.0111$ & [8] \\
\hline Case-fatality of PE during treatment & 0.015 & $0.0091-0.0209$ & {$[32]$} \\
\hline Case-fatality of PE asymptomatic & 0.270 & $0.164-0.376$ & {$[33]$} \\
\hline Case-fatality of PE immediately & 0.220 & $0.134-0.306$ & {$[33]$} \\
\hline Case-fatality of DVT (proximal or distal) during treatment & 0.004 & $0.0024-0.0056$ & {$[32]$} \\
\hline \multicolumn{4}{|l|}{ Annual probability of recurrent VTE } \\
\hline Year 1-2 & 0.081 & $0.049-0.113$ & {$[21]$} \\
\hline Year 3-5 & 0.029 & $0.018-0.041$ & {$[22]$} \\
\hline
\end{tabular}


Table 1 continued

\begin{tabular}{|c|c|c|c|}
\hline Parameters & Base-case value & Range tested & $\overline{\text { References }}$ \\
\hline Annual probability of idiopathic VTE & 0.002 & $0.0014-0.0032$ & {$[8]$} \\
\hline Recurrent VTE is a PE & 0.300 & $0.182-0.418$ & {$[23]$} \\
\hline Idiopathic VTE is a PE & 0.300 & $0.182-0.418$ & {$[15]$} \\
\hline Recurrent DVT is a proximal DVT & 0.660 & $0.401-0.919$ & {$[34]$} \\
\hline Annual probability of PTS from treated DVT & & & {$[22]$} \\
\hline Year 1 & 0.180 & $0.109-0.251$ & \\
\hline Year 2 & 0.079 & $0.048-0.110$ & \\
\hline Year 3-5 & 0.023 & $0.014-0.032$ & \\
\hline Annual probability of PTS from untreated VTE & 0.0012 & $0.0007-0.0017$ & {$[8]$} \\
\hline Annual probability of idiopathic PTS & 0.0008 & $0.0005-0.0011$ & {$[35]$} \\
\hline Annual probability of CTEPH from treated PE & & & {$[24]$} \\
\hline Year 1 & 0.031 & $0.019-0.043$ & \\
\hline Year 2 & 0.007 & $0.0043-0.0097$ & \\
\hline
\end{tabular}

$D V T$ deep vein thrombosis, $P E$ pulmonary embolism, $V T E$ venous thromboembolism, $C T E P H$ chronic thromboembolic pulmonary hypertension, $M B$ major bleeding, $P T S$ post-thrombotic syndrome

${ }^{a}$ Risk ratio was estimated on the basis of the network meta-analysis

treated with rivaroxaban or apixaban versus enoxaparin [20].

In the Markov process, patients with a VTE history might suffer a recurrent VTE and develop post-PTS (in patients who suffered a DVT) or CTEPH (in patients who suffered a PE). The risk of recurrent VTE in the first and second year was taken from an east Asian cohort study [21], and the risks in subsequent years were gathered from an 8-year follow-up observation study [22]. The proportion of PE in recurrent VTE was 30\% in the Eastern population [23]. The probabilities of developing PTS were obtained from a published epidemiological study, which enrolled 528 consecutive patients with a first episode of venography-confirmed DVT [22]. The incidence of CTEPH after PE was obtained from a prospective, long-term, follow-up study of 223 consecutive patients with acute PE [24]. Because of the absence of long-term observational data, we assumed that the risk of CTEPH would be considered only in the first 2 years. The risks of idiopathic VTE and PTS among patients without a history of VTE were assumed to be the same as those of the general population, and the estimates of these risks were referenced to findings in the relevant published literature [8]. The background mortality in the Markov process was obtained from the Chinese life expectancy tables of the World Health Organization's (WHO) member states (2011) [25] and was assigned to all patients regardless of health status [11].

When patients experienced recurrent or idiopathic VTE during the Markov process, they went through the disease course and treatment pattern shown in the decision tree. The relevant probabilities in the decision tree 
were obtained from the relevant published literature $[15,23,26]$ and were assumed to be the same for the three agents.

\section{Costs and Resource Use}

The analysis was conducted from the perspective of the Chinese healthcare system. In the analysis, the direct medical costs included the retail prices of drugs, management costs associated with VTE or bleeding, treatment procedures and follow-up visits, and the costs related to each permanent condition (PTS or CTEPH care).

The purchase prices of rivaroxaban, apixaban, and enoxaparin therapy were obtained from an IMS China Hospital Pharmaceutical Audit (CHPA) database in 2015; the cost of enoxaparin was that of Clexane, which is the highest sold enoxaparin in China. The mean duration (35 days) of prophylaxis in the THR trials was assumed $[18,19]$. No administration cost was assumed for rivaroxaban and apixaban, and the injection cost of enoxaparin per unit was derived from the reported Chinese analyses [36, 37]. The direct costs of each complication are summarized in Table 2. The event cost of symptomatic DVT or PE considered both the diagnosis and the hospitalization cost incurred by the event, and the input value was reviewed and confirmed by physicians in clinical practice in China. Patients with symptomatic VTE after discharge were assumed to switch to warfarin therapy for 6 months, and the total costs of anticoagulation were assumed to be the same as those of patients with mechanical prosthesis aortic valve replacement who received warfarin anticoagulation treatment [38]. The resource use in managing a major bleeding event was based on a Chinese study analyzing the costs for inpatient admissions due to major bleeding events [39]. No cost was assumed for a minor bleeding event because the cost incurred tends to be negligible (on the basis of expert opinion). The long-term resource use associated with PTS and CTEPH included the diagnosis and treatment costs in the first year and treatment costs in the subsequent year [36, 37]. The resource utilization for managing VTE in the Markov process was assumed to be the same as that in the acute phase of the model.

\section{Utility Scores}

QALYs were estimated by weighting life-years by utilities. The utility scores of symptomatic DVT, PE, PTS, MB, THR, and CTEPH were based on estimates reported in previous publications $[8,43-45]$ and are summarized in Table 2 . The utility score of 0.941 for the general population was assumed for the post-operational period until death or the end of the simulation [5]. The same was assumed for patients with asymptomatic VTE and no complications $[36,37]$. The duration of the disease course was estimated to be 6 months for PE and 3 months for symptomatic DVT based on a consensus of Chinese experts [5]. The utility scores were estimated by considering the scores for THR and other joint events such as DVT and PE along the decision tree [46]. In the Markov process, patients in the health states of "no VTE", "untreated VTE", "treated PE", and "treated DVT" were assigned general population utility scores $[8,36]$. The utility scores of transitory VTE events in the Markov process were modeled on the basis of the duration of treatment [8-10].

\section{Sensitivity Analyses}

To explore the model robustness, univariate and probabilistic sensitivity analyses (PSA) were 
Table 2 Patient costs and utility estimates

\begin{tabular}{|c|c|c|c|}
\hline Parameters & $\begin{array}{l}\text { Base-case } \\
\text { value }\end{array}$ & Range tested & Reference \\
\hline \multicolumn{4}{|l|}{ Cost (US \$) } \\
\hline $\begin{array}{l}\text { Enoxaparin } 40 \mathrm{mg} \text { per day (including administration } \\
\text { fee per unit) }\end{array}$ & 8.94 & $4.48-8.94^{\mathrm{a}}$ & $\begin{array}{l}2015 \text { IMS CHPA database } \\
\quad[36,37]\end{array}$ \\
\hline Rivaroxaban $10 \mathrm{mg}$ per day & 13.30 & $6.65-13.30^{\mathrm{a}}$ & 2015 IMS CHPA database \\
\hline Apixaban $5 \mathrm{mg}$ per day & 14.63 & $7.32-14.63^{\mathrm{a}}$ & 2015 IMS CHPA database \\
\hline Diagnosis of PE per unit & 112.07 & $84.05-140.09$ & {$[36]$} \\
\hline Diagnosis of DVT per unit & 68.50 & $51.37-85.62$ & {$[36]$} \\
\hline Management of inpatient PE per event & 1296.12 & $490.97-1964.27$ & {$[40]$} \\
\hline Management of inpatient DVT per event & 871.18 & $360.13-1030.74$ & {$[41]$} \\
\hline Anticoagulation for 6 months after VTE discharge & 96.25 & $72.19-120.31$ & {$[38]$} \\
\hline Management of MB per event & 716.11 & $687.44-744.78$ & {$[39]$} \\
\hline CTEPH diagnosis per event & 306.67 & $186.46-424.44$ & {$[36,42]$} \\
\hline CTEPH treatment per year & $33,028.30$ & $32,063.81-88,000$ & {$[42]$} \\
\hline PTS-first year & 1323.03 & $804.4-1831.07$ & {$[37]$} \\
\hline PTS-subsequent years & 624.60 & $379.76-864.45$ & {$[37]$} \\
\hline \multicolumn{4}{|l|}{ Utility values } \\
\hline Asymptomatic VTE/general population & 0.941 & $0.75-1$ & {$[8]$} \\
\hline Symptomatic DVT for 3 months & 0.81 & $0.55-0.94$ & {$[43]$} \\
\hline PE for 6 months & 0.75 & $0.45-0.91$ & {$[43]$} \\
\hline MB for 1 week & 0.55 & $0.15-0.86$ & {$[43]$} \\
\hline PTS & 0.962 & $0.93-0.98$ & {$[8]$} \\
\hline THR for 6 months & 0.805 & $0.604-1$ & {$[44]$} \\
\hline СТЕРН & 0.63 & $0.52-0.73$ & {$[45]$} \\
\hline
\end{tabular}

$D V T$ deep vein thrombosis, $P E$ pulmonary embolism, $V T E$ venous thromboembolism, $C T E P H$ chronic thromboembolic pulmonary hypertension, $M B$ major bleeding, $P T S$ post-thrombotic syndrome, $T H R$ total hip replacement, $C H P A$ China Hospital Pharmaceutical Audit

${ }^{a}$ Half prices of enoxaparin and apixaban were used for the one-way sensitivity analysis

conducted. In the PSA, key model parameters were simultaneously and randomly sampled from the set parametric distributions to produce 1000 estimates of the cost and QALY for each pair of interventions of the comparison of interest. A gamma distribution was selected for the cost parameters and the beta distribution for probability, proportion, and preference value parameters. On the basis of the results of the PSA, a cost-effectiveness acceptability curve (CEAC) was presented. Univariate sensitivity analyses were conducted for all parameters, and the estimated range of each parameter was either based on the reported or estimated 95\% 
Table 3 Base-case results: rivaroxaban and apixaban versus enoxaparin

\begin{tabular}{|c|c|c|c|}
\hline Strategies & Enoxaparin & Rivaroxaban & Apixaban \\
\hline Cost (US \$) & 359.94 & 511.50 & 538.64 \\
\hline QALY & 4.4890 & 4.4826 & 4.4915 \\
\hline $\operatorname{ICER}(\$ / Q A L Y)^{a}$ & - & Dominated & 71,244 \\
\hline
\end{tabular}

QALY quality-adjusted life year, ICER incremental cost-effectiveness ratio

${ }^{a}$ Compared with enoxaparin

confidence intervals in the referenced studies or determined by assuming a $25 \%$ change in the base-case value, except for the branded drugs (apixaban and enoxaparin), whose prices were assumed to be reduced by $50 \%$ because the negotiations of Chinese national drug prices always request that the prices of branded drugs be sharply reduced (Table 2). Instead of the incremental cost-effectiveness ratio for which statistical inference is often difficult [47], the incremental net-health benefit (INHB), a linear transformation of incremental costs and effectiveness, was utilized with the following formula: $\operatorname{INHB}(\lambda)=\left(\mu_{\mathrm{E}-\text { treatment }}-\mu_{\mathrm{E}-\mathrm{control}}\right) \times \lambda$ $-\left(\mu_{\mathrm{C} \text {-treatment }}-\mu_{\mathrm{C} \text {-control }}\right) / \lambda=\Delta E-\Delta C / \lambda$, where $\mu_{\mathrm{C}}$ and $\mu_{\mathrm{E}}$ are the population's average cost and effectiveness of the treatment or control, respectively [48], and $\lambda$ is three times the GDP per capita of China in 2014 as willingness-to-pay (WTP) threshold that was generally recommended by the Chinese guidelines for pharmacoeconomic evaluations [16]. The model development and data analysis were conducted using Microsoft ${ }^{\circledR}$ Excel 2013 (Microsoft, Redmond, WA, USA).

\section{Compliance with Ethics Guidelines}

This article is based on previously conducted studies and does not involve any new studies of human or animal subjects performed by any of the authors.

\section{RESULTS}

\section{Base-Case Analysis}

Compared with enoxaparin, 35 days of prophylaxis with rivaroxaban and apixaban increased the cost by US $\$ 151.56$ and US $\$ 178.70$, respectively (Table 3 ). Rivaroxaban resulted in 0.0064 fewer QALYs than enoxaparin, and apixaban yielded 0.0025 QALYs more than enoxaparin. Therefore, rivaroxaban was inferior to enoxaparin, and the ICER of apixaban over enoxaparin was US $\$ 71,244 /$ QALY.

\section{Sensitivity Analysis}

In the comparison between rivaroxaban and enoxaparin, the most sensitive parameters included the risk ratio of $\mathrm{PE}$ and the cost of rivaroxaban (Fig. 2); changes in these factors might yield substantial changes in the net health benefits in Chinese patients with THR. Compared with that of enoxaparin, the cost of apixaban was the most sensitive parameter. If the cost of apixaban decreased by $50 \%$, the gain in net health benefits would be higher than zero. Other parameters, such as the cost of enoxaparin and the risk ratio of $\mathrm{PE}$, had a moderate or weak effect on the model outcome. In general, these analyses suggest that the model outcomes were robust. 
A

HR of PE for rivaroxaban versus enoxaparin

Cost of rivaroxaban $10 \mathrm{mg}$ per day

$\mathrm{HR}$ of $\mathrm{MB}$ for rivaroxaban versus enoxaparin

$\mathrm{PE}$ is symptomatic (excluding immediately fatal)

Proximal DVT is symptomatic

Utility General population
Net health benefit $=0$ QALY
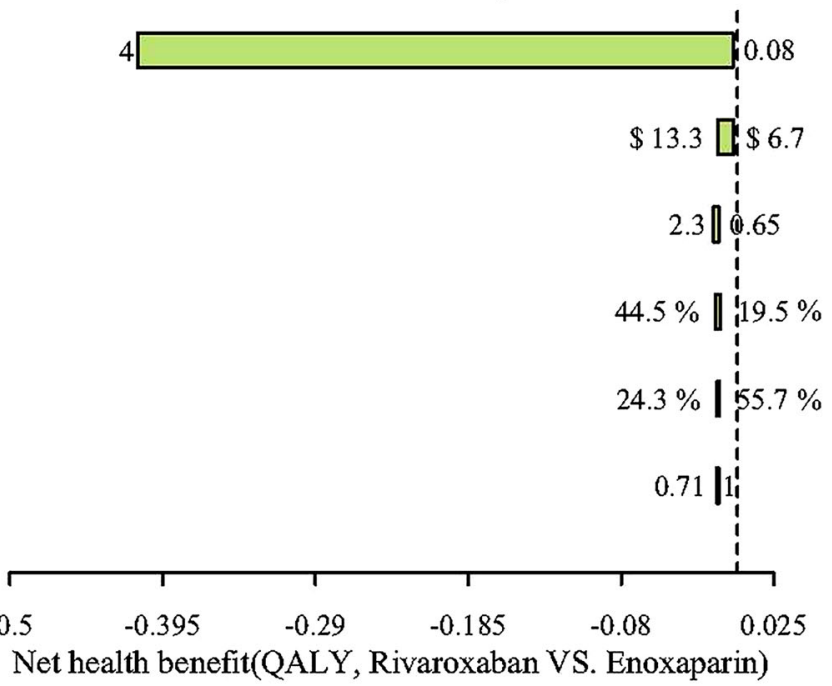

B

Cost of apixaban 10mg per day

HR of PE for Apixaban versus enoxaparin

Utility General population

HR of Proximal DVT for Apixaban versus enoxaparin

Proximal DVT is symptomatic

Recurrent VTE is a PE

Utility Deep vein thrombosis without TKR/THR

Case-fatality of PE immediately

HR of Distal DVT for Apixaban versus enoxaparin

Developing recurrent VTE: year 1
Net health benefit $=0$ QALY

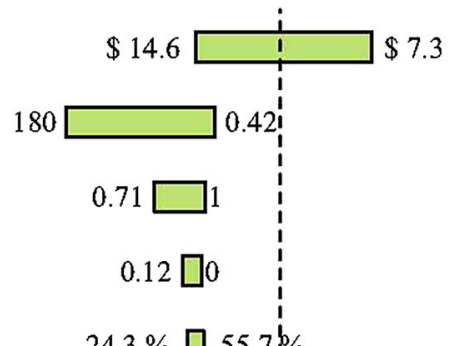

$24.3 \% \square 55.7 \%$

$18.2 \% \square 41.8 \%$

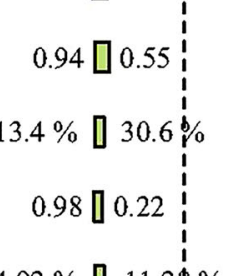

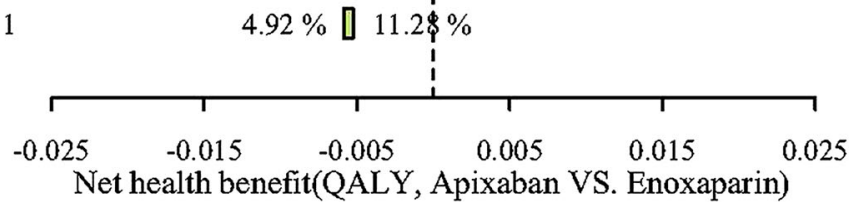

Fig. 2 Univariate sensitivity analyses for rivaroxaban versus enoxaparin (a) and apixaban versus enoxaparin (b). $D V T$ deep vein thrombosis, $P E$ pulmonary embolism, $V T E$ venous thromboembolism, $H R$ hazard ratio

The results of the PSA of THR are shown in the cost-effectiveness acceptability curves (Fig. 3); the proportions of the simulations in which rivaroxaban, apixaban, and enoxaparin were cost-effective were $0.00 \%, 0.00 \%$, and $100.00 \%$, respectively, at a cost-effectiveness threshold of US $\$ 22,140$ (three times GDP per capita of China in 2014). 


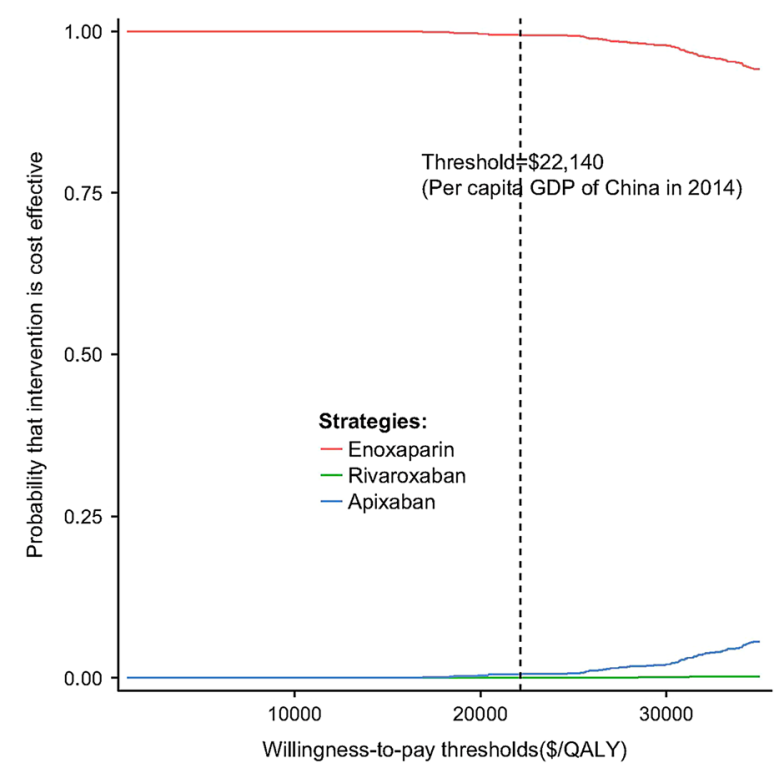

Fig. 3 Acceptability curves regarding the cost-effectiveness of rivaroxaban, apixaban, and enoxaparin. QALY quality-adjusted life-year

\section{DISCUSSION}

The current study examined the cost-effectiveness of three potentially competing thromboprophylactic agents, including two new oral anticoagulants (rivaroxaban and apixaban) and one low molecular weight heparin (enoxaparin), which is recommended in current Chinese clinical practice. By combing the decision tree used for acute events (180 days) and the Markov model used for long-term complications (5 years), we found that the extrapolated results were inconsistent with the projections reported by Sullivan et al. and others [7-13]. The results of this study were based on the current understanding of the natural history of VTE and the best available clinical evidence, which provides reliable information for decision-making in reimbursement listing and the allocation of healthcare resources.

Our analysis suggests that patients receiving enoxaparin for prophylaxis would gain more health benefits and incur lower overall costs for up to 5 years in comparison with rivaroxaban in a cohort population of Chinese patients after THR. Thrombophylaxis with apixaban in place of enoxaparin would generate more QALYs but a higher total cost and result in an ICER of US $\$ 71,244 /$ QALY, which is far higher than the threshold of US $\$ 22,140$ (three times GDP per capita of China in 2014). Therefore, enoxaparin is a cost-effective and dominant strategy in patients undergoing THR surgery in China. The potential reason for the increased QALYs gained by enoxaparin versus rivaroxaban might be the fewer events of PE that further lead to a smaller incidence of CTEPH and mortality. Our study highlights that the presence of these clinical complications are the key QALY drivers. Overall, lower complication costs were estimated for patients who received enoxaparin, which has also been shown to have lower risks for such complications. The results should be carefully explained because of the small QALY differences and their associated uncertainties. A small adjustment of the key parameters might result in a great change of the ICER of rivaroxaban and apixaban versus enoxaparin.

Our study findings that rivaroxaban and apixaban were not cost-effective in comparison with enoxaparin were inconsistent with the conclusions reported in previous studies [11, 12, 37]. One plausible explanation for this discrepancy is that unlike the previous studies that have included one local Chinese economic evaluation comparing apixaban and enoxaparin, our model considered and included CTEPH after a PE event as one long-term complication, which was not included as a Markov health state in other studies [11, 14]. The prognosis and quality of life of CTEPH patients are poor, and the 3-year survival rate has been reported to be as low as $40 \%$ in 
patients with a mean pulmonary arterial pressure greater than $30 \mathrm{mmHg}$ [49]. Furthermore, the cost of managing CTEPH was expected to be nearly $€ 36,768$ per year, as shown in a study analyzing the data of six European countries [26]. The disease burden related to CTEPH is also high in China [42]. Owing to this non-negligible cost, the effect of CTPEH could not be, and was not, ignored in this study. The second reason is that the time horizon of the chronic phase in our analysis was 5 years, which might underestimate the benefits of new oral anticoagulants by reducing the risks of DVT because the PTS caused by DVT would affect the health for a long time as other studies had done $[8,10]$. The third explanation for differences between this and previous studies is the higher cost of new oral anticoagulants and lower costs of enoxaparin and managing VTE events in China in comparison with those in developed countries [7-13], thus explaining the relatively lower offset of the costs of new oral anticoagulants, including both rivaroxaban and apixaban, in China.

In the comparison between rivaroxaban and enoxaparin, the results of base-case analysis were insensitive to adjustments in key parameters, except for the purchase price of rivaroxaban. This evidence further indicated that the benefit of enoxaparin in reducing the risk of $\mathrm{PE}$ and its complications had a considerable effect on the model outcomes. Therefore, enoxaparin might improve outcomes at a lower total cost for thromboprophylaxis in THR patients at high risk of PE, such as those with a previous PE [24]. The results of univariate analysis for apixaban against enoxaparin show the robustness of the ICER to the changes in input estimates except for the purchase price of apixaban.

This study also had several limitations. First, because the lack of head-to-head treatment results for these three strategies, the efficacy and safety data of the prophylactic agents were derived from different randomized controlled treatment results. To minimize the potential bias and uncertainty in the outcomes, we used widely accepted robust techniques to estimate the event rate and tested the effects by using sensitivity analyses. Second, the current analysis did not weigh the risks of stroke and myocardial infarction caused by embolisms and secondary events such as death. However, findings from the trials suggested that there were no statistically significant differences in cardiovascular outcomes among rivaroxaban, apixaban, and enoxaparin $[18,19]$. Third, our study did not address quality-of-life impairment attributed to the daily injection of enoxaparin. On the basis of the opinions of experts, there is no evidence showing that short-term treatment with enoxaparin affects the quality of life of THR patients. Fourth, a number of assumptions that were made in the model to extrapolate the results, such as the long-term risks of VTE, PTS, and CTEPH, might have introduced additional uncertainties in our analysis [14]. We attempted to conduct an extensive sensitivity analysis to test the effects of these potential uncertainties on the cost-effectiveness results. Finally, as a result of the absence of the explicit WTP threshold in China, the current analysis used the three times the GDP per capita of China in 2014 as the WTP threshold, which might be varied by depending on several factors. However, the uncertainties in these parameters could be further reduced with the availability of long-term follow-up clinical data for these events.

\section{CONCLUSION}

To our knowledge, this is the first economic evaluation study conducted in China to assess the cost-effectiveness of VTE prophylaxis with 
rivaroxaban and apixaban versus enoxaparin in Chinese patients after THR and in which all possible known long-term complications were considered. Our study indicates that enoxaparin thromboprophylaxis in Chinese patients after THR is still likely to be cost-effective.

\section{ACKNOWLEDGEMENTS}

Sponsorship for this study was funded by Sanofi China. No sponsorship was received for the publication of this article. However, the study sponsor had no influence on the study design, data collection or writing of the manuscript. All named authors meet the International Committee of Medical Journal Editors (ICMJE) criteria for authorship for this manuscript, take responsibility for the integrity of the work as a whole, and have given final approval for the version to be published. The authors thank Seng Chuen Tan and Xingzhi Wang for reviewing and editing the manuscript. The authors would also like to thank the two anonymous reviewers for their constructive suggestions that helped to improve the final version of the paper considerably and acknowledged this in the manuscript. All data generated or analyzed during this study are included in this published article.

Compliance with Ethics Guidelines. This article is based on previously conducted studies and does not involve any new studies of human or animal subjects performed by any of the authors.

Disclosures. Dr. Wu has received a consulting fee from Sanofi China. Xiaoyu Yan, Xiaohua $\mathrm{Gu}$, Zhenxing $\mathrm{Xu}$, and Houweng Lin have nothing to disclose.
Open Access. This article is distributed under the terms of the Creative Commons Attribution-NonCommercial 4.0 International License (http://creativecommons.org/licenses/ by-nc/4.0/), which permits any noncommercial use, distribution, and reproduction in any medium, provided you give appropriate credit to the original author(s) and the source, provide a link to the Creative Commons license, and indicate if changes were made.

\section{REFERENCES}

1. Goldhaber SZ, Bounameaux H. Pulmonary embolism and deep vein thrombosis. Lancet. 2012;379(9828):1835-46.

2. Ruppert A, Steinle T, Lees M. Economic burden of venous thromboembolism: a systematic review. J Med Econ. 2011;14(1):65-74.

3. Piovella F, Wang CJ, Lu H, Lee K, Lee LH, Lee WC, et al. Deep-vein thrombosis rates after major orthopedic surgery in Asia. An epidemiological study based on postoperative screening with centrally adjudicated bilateral venography. J Thromb Haemost JTH. 2005;3(12):2664-70.

4. Geerts WH, Bergqvist D, Pineo GF, Heit JA, Samama $\mathrm{CM}$, Lassen MR, et al. Prevention of venous thromboembolism. Chest. 2008;133(6):381S-453S.

5. Association OTToCO. Consensus on deep venous thrombosis screening for patients with orthopaedic trauma. Chin J Orthop Trauma. 2013;15(12):1013-7.

6. Gomez-Outes A, Terleira-Fernandez AI, Suarez-Gea ML, Vargas-Castrillon E. Dabigatran, rivaroxaban, or apixaban versus enoxaparin for thromboprophylaxis after total hip or knee replacement: systematic review, meta-analysis, and indirect treatment comparisons. BMJ. 2012;344:e3675.

7. Sullivan SD, Kahn SR, Davidson BL, Borris L, Bossuyt P, Raskob G. Measuring the outcomes and pharmacoeconomic consequences of venous thromboembolism prophylaxis in major orthopaedic surgery. Pharmacoeconomics. 2003;21(7):477-96. 
8. McCullagh L, Walsh C, Barry M. Value-of-information analysis to reduce decision uncertainty associated with the choice of thromboprophylaxis after total hip replacement in the Irish healthcare setting. Pharmacoeconomics. 2012;30(10):941-59.

9. Wolowacz SE, Roskell NS, Maciver F, Beard SM, Robinson PA, Plumb JM, et al. Economic evaluation of dabigatran etexilate for the prevention of venous thromboembolism after total knee and hip replacement surgery. Clin Ther. 2009;31(1):194-212.

10. Botteman MF, Caprini J, Stephens JM, Nadipelli V, Bell CF, Pashos CL, et al. Results of an economic model to assess the cost-effectiveness of enoxaparin, a low-molecular-weight heparin, versus warfarin for the prophylaxis of deep vein thrombosis and associated long-term complications in total hip replacement surgery in the United States. Clin Ther. 2002;24(11):1960-86 (discussion 38).

11. Diamantopoulos A, Lees M, Wells PS, Forster F, Ananthapavan J, McDonald H. Cost-effectiveness of rivaroxaban versus enoxaparin for the prevention of postsurgical venous thromboembolism in Canada. Thromb Haemost. 2010;104(4):760-70.

12. Ryttberg L, Diamantopoulos A, Forster F, Lees M, Fraschke A, Bjorholt I. Cost-effectiveness of rivaroxaban versus heparins for prevention of venous thromboembolism after total hip or knee surgery in Sweden. Expert Rev Pharmacoecon Outcomes Res. 2011;11(5):601-15.

13. Gordois A, Posnett J, Borris L, Bossuyt P, Jonsson B, Levy $\mathrm{E}$, et al. The cost-effectiveness of fondaparinux compared with enoxaparin as prophylaxis against thromboembolism following major orthopedic surgery. J Thromb Haemost JTH. 2003;1(10):2167-74.

14. Duran A, Sengupta N, Diamantopoulos A, Forster F, Kwong L, Lees M. Cost effectiveness of rivaroxaban versus enoxaparin for prevention of post-surgical venous thromboembolism from a U.S. payer's perspective. Pharmacoeconomics. 2012;30(2): 87-101.

15. Moser KM, LeMoine JR. Is embolic risk conditioned by location of deep venous thrombosis? Ann Intern Med. 1981;94(4 pt 1):439-44.

16. Task Group of the Chinese Guidelines for Pharmacoeconomic Evaluations. China J Pharm Econ. 2011;6(3):7-48.

17. Eichler HG, Kong SX, Gerth WC, Mavros P, Jonsson B. Use of cost-effectiveness analysis in health-care resource allocation decision-making: how are cost-effectiveness thresholds expected to emerge? Value Health. 2004;7(5):518-28.

18. Eriksson BI, Borris LC, Friedman RJ, Haas S, Huisman MV, Kakkar AK, et al. Rivaroxaban versus enoxaparin for thromboprophylaxis after hip arthroplasty. N Engl J Med. 2008;358(26):2765-75.

19. Lassen MR, Gallus A, Raskob GE, Pineo G, Chen D, Ramirez LM, et al. Apixaban versus enoxaparin for thromboprophylaxis after hip replacement. N Engl J Med. 2010;363(26):2487-98.

20. Dias S, Sutton AJ, Ades AE, Welton NJ. Evidence synthesis for decision making 2: a generalized linear modeling framework for pairwise and network meta-analysis of randomized controlled trials. Med Decis Making. 2013;33(5):607-17.

21. Nakamura M, Miyata T, Ozeki Y, Takayama M, Komori K, Yamada N, et al. Current venous thromboembolism management and outcomes in Japan. Circ J. 2014;78(3):708-17.

22. Prandoni P, Villalta S, Bagatella P, Rossi L, Marchiori A, Piccioli A, et al. The clinical course of deep-vein thrombosis. Prospective long-term follow-up of 528 symptomatic patients. Haematologica. 1997;82(4):423-8.

23. Nakamura $\mathrm{M}$, Yamada $\mathrm{N}$, Ito $\mathrm{M}$. Current management of venous thromboembolism in Japan: current epidemiology and advances in anticoagulant therapy. J Cardiol. 2015;66(6):451-9.

24. Pengo V, Lensing AW, Prins MH, Marchiori A, Davidson BL, Tiozzo F, et al. Incidence of chronic thromboembolic pulmonary hypertension after pulmonary embolism. $\mathrm{N}$ Engl J Med. 2004;350(22):2257-64.

25. Life tables for WHO Member States. http://www. who.int/healthinfo/statistics/mortality_life_tables/ en/. Accessed 18 Sept 2012.

26. Schweikert B, Pittrow D, Vizza CD, Pepke-Zaba J, Hoeper MM, Gabriel A, et al. Demographics, clinical characteristics, health resource utilization and cost of chronic thromboembolic pulmonary hypertension patients: retrospective results from six European countries. BMC Health Serv Res. $2014 ; 14: 246$.

27. Oster G, Tuden RL, Colditz GA. A cost-effectiveness analysis of prophylaxis against deep-vein thrombosis in major orthopedic surgery. Jama. $1987 ; 257(2): 203-8$.

28. Menzin J, Colditz GA, Regan MM, Richner RE, Oster G. Cost-effectiveness of enoxaparin vs low-dose warfarin in the prevention of deep-vein thrombosis 
after total hip replacement surgery. Arch Intern Med. 1995;155(7):757-64.

29. Nerurkar J, Wade WE, Martin BC. Cost/death averted with venous thromboembolism prophylaxis in patients undergoing total knee replacement or knee arthroplasty. Pharmacotherapy. 2002;22(8):990-1000.

30. Rubinstein I, Murray D, Hoffstein V. Fatal pulmonary emboli in hospitalized patients. An autopsy study. Arch Intern Med. 1988;148(6):1425-6.

31. Lagerstedt CI, Olsson CG, Fagher BO, Oqvist BW, Albrechtsson U. Need for long-term anticoagulant treatment in symptomatic calf-vein thrombosis. Lancet. $1985 ; 2(8454): 515-8$.

32. Douketis JD, Kearon C, Bates S, Duku EK, Ginsberg JS. Risk of fatal pulmonary embolism in patients with treated venous thromboembolism. Jama. 1998;279(6):458-62.

33. Stein PD, Henry JW. Prevalence of acute pulmonary embolism among patients in a general hospital and at autopsy. Chest. 1995;108(4):978-81.

34. Hansson PO, Sorbo J, Eriksson H. Recurrent venous thromboembolism after deep vein thrombosis: incidence and risk factors. Arch Intern Med. 2000;160(6):769-74.

35. Heit JA, Rooke TW, Silverstein MD, Mohr DN, Lohse CM, Petterson TM, et al. Trends in the incidence of venous stasis syndrome and venous ulcer: a 25-year population-based study. J Vasc Surg. 2001;33(5):1022-7.

36. Xingbao C, Eggington S, Caiyun W, Min ZHU. Cost-effectiveness study of rivaroxaban for the prevention of venous thromboembolism in patients under going total knee replacement. China Pharm. 2011;22(30):2787-90.

37. Bao L, Xiaoping $\mathrm{X}$, Yue $\mathrm{G}$, Zhengang $\mathrm{C}$. Cost-effectiveness of apixaban compared with enoxaparin for prevention of venous thromboembolism after major orthopedic surgery in China. Chin J Joint Surg (Electronic Version). 2014;8(5):677-81.

38. Xu H, Zhang Y, Liu L, Zou R. Warfarin dosing and pharmacoeconomic evaluation in patients after mechanical prosthesis aortic valve replacement. Acta Acad Med Jiangxi. 2009;49(12):102-5.
39. Zhou J, Li B. Cost-effectiveness analysis of endoscope and omprazole in the treatment of acute hemorrhage of upper digestive tract. Lingnan J Emerg Med. 2013;18(6):453-6.

40. Wang Y, Zheng Y, Cai S, Fang L, Ni P. Efficacy and economics analysis of two anticoagulant schemes in the treatment of inpatients with pulmonary embolism. Chin J Drug Appl Monit. 2010;7(4):200-4.

41. Cao S. Pharmacoeconomic analysis of four strategies for treating deep vein thrombosis. J Huaihai Med. 2009;27(4):355-6.

42. Shen J, Sun Y, Liu H, Yao T, Bu J, Shen L, et al. Study on the cost-effect of combined therapy for patients with pulmonary arterial hypertension. J Intern Med Concepts Pract. 2008;3(6):416-9.

43. Hogg K, Kimpton M, Carrier M, Coyle D, Forgie M, Wells P. Estimating quality of life in acute venous thrombosis. JAMA Intern Med. 2013;173(12):1067-72.

44. Rasanen $\mathrm{P}$, Paavolainen $\mathrm{P}$, Sintonen $\mathrm{H}$, Koivisto AM, Blom M, Ryynanen OP, et al. Effectiveness of hip or knee replacement surgery in terms of quality-adjusted life years and costs. Acta Orthop. 2007;78(1):108-15.

45. Garin MC, Clark L, Chumney EC, Simpson KN, Highland KB. Cost-utility of treatments for pulmonary arterial hypertension: a Markov state-transition decision analysis model. Clin Drug Investig. 2009;29(10):635-46.

46. Bo $\mathrm{H}, \mathrm{Fu} \mathrm{AZ}$. Predicting utility for joint health states: a general framework and a new nonparametric estimator. Med Decis Making. 2010;30(5):E29-39.

47. Briggs A, Fenn P. Confidence intervals or surfaces? Uncertainty on the cost-effectiveness plane. Health Econ. 1998;7(8):723-40.

48. Craig BA, Black MA. Incremental cost-effectiveness ratio and incremental net-health benefit: two sides of the same coin. Expert Rev Pharmacoecon Outcomes Res. 2001;1(1):37-46.

49. Lewczuk J, Piszko P, Jagas J, Porada A, Wojciak S, Sobkowicz B, et al. Prognostic factors in medically treated patients with chronic pulmonary embolism. Chest. 2001;119(3):818-23. 